\title{
Safety compliance and prevalence of occupational health and safety incidents among Ghanaian auto artisans
}

\author{
Asamani, Lebbaeus $\bowtie$ \\ University of Ghana, Ghana (lasamani@st.ug.edu.gh

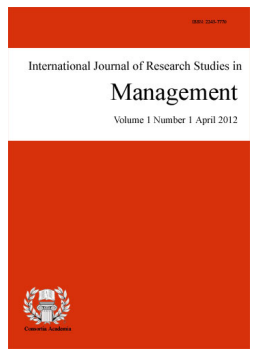

Accepted: 20 April 2018

ISSN: $2243-7770$ Online ISSN: 2243-7789

OPEN ACCESS

\section{Abstract}

The work environment of Ghanaian local auto artisans has over the years consisted of various hazards that have dire health and safety implications. This study examined the extent to which the artisans comply with relevant safety regulations as spelt out in the Factories, Offices and Shops Act, 1970 (Act 328) of Ghana. The study also investigated the prevalence of health and safety challenges and work related injuries among Ghanaian local artisans. The mode of treating health and safety incidents experienced by the artisans was also investigated. One hundred and fifty artisans, comprising 141 males and 9 females were studied in a descriptive survey. The results showed that the work environment of the artisans was not very congenial and most of them did not comply with many of the safety regulations. Several incidents and injuries were experienced by the artisans and a great number of them also reported work-related health challenges. It was also found that about $38 \%$ of the health and safety challenges were treated at the hospital and more than $48 \%$ were self-treated by the artisans. The study concluded that the noncompliance of safe work procedures accounted for most of the health and safety incidents the artisans experienced. Among others, it was recommended that the Inspectorate Directorate of the Ministry of Employment and Labor Relations should extend its inspections and health and safety compliance and education functions to the operations of auto artisans and other informal work settings.

Keywords: auto artisans; informal sector; occupational health and safety; safety compliance; prevalence of occupational incidents 


\section{Safety compliance and prevalence of occupational health and safety incidents among Ghanaian auto artisans}

\section{Introduction}

Occupational health and safety is a basic human right for every worker. This is so important because individuals spend more than three-quarters of their non-sleeping or waking hours at work or in work-related activities. The 1992 constitution and the Labor Act of Ghana emphasize the need for ensuring healthy workforce and provision of decent work. The sustainable development goals (SDG 2030) number eight seeks to "Promote sustained, inclusive and sustainable economic growth, full and productive employment and decent work for all". World Health Organization (WHO) indicated that: "Occupational safety and health is a human right and decent work eventually is safe work (WHO, 2010, p. 1). Thus, if goal 8 seeks to promote economic productivity and decent work, then safe work environment, and conducive work conditions and practices must be of top priority in all sectors.

Although Ghana does not currently have a comprehensive occupational health and safety document, there are different policy documents and Acts that provide guidelines for health and safety in different sectors. For instance, the mining sector has the Mining Regulations 1970 (Government of Ghana, 1970), and the Labor Act 2003 (Government of Ghana, 2003) also has general provisions for all workers. The Factories, Offices and Shops Act (FOSA) 1970 (Government of Ghana, 1970) also provides regulations for ensuring safety and health of workers in all Factories, Offices and Shops in Ghana. This Act (FOSA) indicated that all factories, offices and shops must be registered and given renewable certificates by the Chief Inspector. It also requires the Inspectorate Directorate to carry out periodic inspections and provide remedial measures and sanctions when necessary to prevent adverse consequences at the workplace.

Enforcement and compliance with the provisions in the FOSA would prevent several occupational accidents, injuries and health challenges arising out of work and ensure decent and safe work for artisans and other factory workers. For instance, Section 12 of the Act requires that owners of factories, offices and shops must report every case of industrial diseases and accidents to the Chief Inspector or the Safety Inspector of the district where the factory or shop is located. Other provisions in the act cover areas such as cleanliness of the workplace, overcrowding, ventilation, washing facilities, lighting, accommodation for clothing, sitting facilities training and supervision among others. It however seems the local artisans and other informal sector work settings have been neglected by the enforcement authorities of the safety regulations. As indicated by (Atim, Fleisher, Hatt, Masau, \& Arur, 2009), informal sector workers have largely been sidestepped in the design of national social protection schemes in Ghana. However, a critical look at the FOSA suggests that the informal sector, including artisan and trade works are covered by the enforcement of the provisions is where the challenge lies. The Act (FOSA) defines a Factory as:

“... any premises in which, or within the close or cartilage of which, any person is employed in manual labor in any process for or incidental to any one or more of the following types of work which are carried on by way of trade or for purposes of gain, and to or over which premises the employer of the person employed therein has the right of access or control namely, -

(a) The making of any article or part of any article;

(b) the altering, repairing, ornamenting, finishing, filling, packing, bookbinding, cleaning, washing, breaking up or demolition of any article..."

This clearly indicates that the work settings of the local artisans fall under the definition of a factory in this act, but the enforcement of the provisions is the problem. 
Safety compliance and prevalence of occupational health and safety incidents among Ghanaian auto artisans

The ILO (2014) estimates indicate that a worker dies from work related accident or disease and 153 workers have work related accidents every 15 seconds. The ILO (2015) further indicate that 6300 people die every day from work accidents or work related disease, which means that more than 2.3 million people die every year. Three hundred and seventeen million work-related accidents occur every year and, many of the accidents lead to extended absence from work. Total economic losses due to occupational illnesses and injuries are enormous (WHO, 1999). The World Health Organization estimates further indicate that 160 million new cases of work-related illnesses occur every year and workplace conditions account for over a third of back pain, 16 percent of hearing loss, approximately ten percent of lung cancer. The ILO making global estimates from occupational burden point of view and the WHO from the health view point concluded that all fatalities in industrial countries of about $5-7 \%$ (ILO, 2006) is attributable to work-related illness and occupational injuries.

In Ghana a total of 8,692 work-related accidents were reported to the Department of Labor for compensation claims in the year 2000, while 4,088 were reported in 1999 (Ghana Department of Labor, 1999; 2000). These figures represent only serious incidents that occurred in the formal sector. The annual occupational injury rates of Ghana were estimated at about 11.5 injuries per 1,000 persons in the urban areas, and 44.9 per 1,000 in the rural areas (Mock, Adjei, Acheampong, Deroo, \& Simpson, 2005).

The human cost of occupational accidents, illnesses and injuries is very enormous and the economic cost or burden of poor occupational safety and health practices is estimated at between $1.8-6 \%$ and an average of $4 \%$ of global GDP a year (ILO, 2014). Estimates suggest that the cost of occupational injuries, accidents and diseases in Ghana amount to about 7\% of the country's GDP (Ghana News Agency: GNA, September 18, 2003). Furthermore, about $8 \%$ of precipitating factors of depression were found to be attributable to workplace conditions and hazards (Boden, Biddle, \& Spieler, 2001).

This study is very relevant, given that occupational injuries have higher mortality, longer disability, and higher treatment costs than non-occupational injuries (Mock et al, 2005). Occupational safety and health of all workers must be a top priority at every work setting by safety researchers and practitioners, management of organizations, workers and government. Meanwhile, most research efforts in workplace safety have been largely focused in the formal sector and not much is known about the informal sector workers health and safety issues, such as the local artisans.

This is one of the almost non-existent researches in the informal sector that touched on health and safety, specifically of auto artisans. This study examined the extent to which the local artisans comply with some of the provisions in the act. The study also investigated the prevalence of health challenges and safety concerns among Ghanaian auto artisans, and how they treat occupational injuries.

\subsection{Research Questions}

$>\quad$ To what extent do Ghanaian local artisans comply with safety regulations at their workplaces?

$>\quad$ What are the major health and safety challenges experienced by the local artisans?

$>\quad$ How do the local artisans treat health and safety challenges and injuries suffered at their workplaces?

\section{Research Methodology}

\subsection{Population}

The theoretical population for the study was all local artisans in Ghana which includes auto mechanics, auto sprayers, auto electricians, welders, vulcanizes and carpenters. The Ghana Living Standards Survey (GLSS, 2014) indicated that Ghanaian local artisan were about $10.0 \%$ of the Ghanaian population, while (Osei-Boateng \& Amprateum, 2011) put the figure at $13.4 \%$ of the population. The accessible population comprises local artisans 
Asamani, L.

in the Cape Coast Metropolis.

\subsection{Sample and Sampling Procedure}

The study surveyed a total of 150 artisans, comprising 141(94.0\%) males and 9 (6.0\%) females, with ages ranging from 18 to 59 years. The characteristics of the respondents in the study are presented in table 1 . The purposive sampling procedure was used to get the respondents for the study because the kind of respondents used in the study could not have been obtained through random sampling procedure or any other sampling procedure. I went to a place (Sewdu and its surroundings iCape Coast) where most of the artisans work and interacted with them. Anyone who gave consent to take part in the study was included.

Most of the respondents (80\%) obtained at most Junior High Secondary level of education, with only 5.3\% having tertiary level of education. The respondents with tertiary education happened to be foremen in some of the shops we sampled respondents from. The artisans used in the study include welders (26.7\%), auto mechanics (22.0\%), auto sprayers (20.7\%), auto electricians (20.0\%) and vulcanizes (10.7\%).

\section{Table 1}

Demographic Characteristics of Respondents

\begin{tabular}{|c|c|c|}
\hline Items & Frequencies & Percentages \\
\hline \multicolumn{3}{|l|}{ Gender } \\
\hline Male & 141 & 94.00 \\
\hline Female & 9 & 6.00 \\
\hline Total & 150 & 100.00 \\
\hline \multicolumn{3}{|l|}{ Educational level } \\
\hline No formal education & 26 & 17.33 \\
\hline Basic/JHS & 18 & 12.00 \\
\hline JHS & 73 & 48.67 \\
\hline SHS & 25 & 16.67 \\
\hline Tertiary & 8 & 5.33 \\
\hline Total & 150 & 100.00 \\
\hline \multicolumn{3}{|l|}{ Artisan Types } \\
\hline Welder & 40 & 26.67 \\
\hline Auto Mechanic & 33 & 22.00 \\
\hline Sprayer & 31 & 20.67 \\
\hline Auto Electrician & 30 & 20.00 \\
\hline Vulcanizes & 16 & 10.67 \\
\hline Total & 150 & 100.00 \\
\hline
\end{tabular}

\subsection{Data Collection Instrument (Measures)}

The main data collection tool was a set of survey questionnaire in addition to the demographic data. The questionnaire covers items that assessed the extent to which the artisans complied with some of the health and safety regulations in Act 328. There were also items that assessed the prevalence of health and safety challenges among the artisans.

Demographic information of respondents - The demographic information of the respondents, such as their sex, age, type of artisan work and educational level, were contained at the beginning of the questionnaire. These were all coded as nominal measures.

Compliance with health and safety regulations - The items for the compliance with health and safety regulations were generated from relevant portions of the sections of the Factories, Offices and Shops Act, 1970. This section consists of 10 items that assessed the extent to which the artisans complied with relevant provisions in the Act. An example is whether the artisans had first aid box or cupboard at their shops at the time of the study and they were to respond either yes or no. To ensure validity of their responses, I observed to verify the existence 
Safety compliance and prevalence of occupational health and safety incidents among Ghanaian auto artisans

and compliance of the provisions.

Health and safety challenges - The prevalence of health and safety challenges was measured with 20 items regarding occupational incidents, such as accidents, injuries, near misses and health problems. The items were taken from incident reporting rate questionnaire (Barling, Loughlin, \& Kelloway, 2002). The scale has been used widely to measure occupational health and safety incidents and was found to be very reliable. Previous studies that used the sale reported high internal reliability alpha ranging from .70 to .89 , and also found to have good validity (e.g. Barling et al., 2002; Munteanu, 2005). The original scale consists of 27 incidents, but seven of them were deemed not appropriate or relevant for the present study. Respondents were asked to indicate how frequently they experienced various health and safety incidents within the past 12 months, on a 5-point Likert scale from 1 (never) to 5 (more than 5 times). An item was also included to find out how the artisans treated any health and safety challenges and injuries they experienced at the workplace.

\subsection{Reliability and Validity of Measures}

To ensure content validity and relevance of the measures, I had discussions with officers and foremen of the maintenance section of the University of Cape Coast, to ensure that the items were relevant for the artisan work settings. A pilot testing of the study protocol was done to ensure the measures were appropriate and reliable for use in the present study. The pilot study was done with 30 artisans conveniently selected for that purpose. There were no major issues with any of the items on the questionnaire. The results of the pilot test showed that the measures were reliable and appropriate. A reliability coefficient of .73 was obtained for the compliance with health and safety regulations scale, and 87 for the health and safety incidents scale. The reliability coefficients for the final study were also .81 and .83 for the two scales respectively.

\subsection{Data Analysis Procedure}

The data analysis was mainly descriptive. The demographic information of the respondents was analyzed with frequency and percentages. The conditions of the work environment of the artisans, the percentages of the prevalence of various health and safety incidents among the artisans were also presented in percentages.

\subsection{Limitation of the Study}

The finding of the study must be interpreted with caution in light of certain limitations. First of all, the data collection instrument was a self-report questionnaire. The responses might reflect the actual state on the ground. However, I did personal observations and checks on some of the responses given by the respondents. For instance, if a respondent indicated that there was a first-aid box at the workplace, I verified if the box was actually there. Another area of caution with regard to the findings has to do with the fact that the study was conducted among auto artisans only, and so the finding may not apply to artisans in other work settings. For instance, there are welders and electricians who work in other settings in the informal sector of the Ghanaian economy. The health and safety situation of artisans in the auto work settings might be different from those in other areas, e.g. building and construction.

\section{Results}

Research Question 1: To extent what do Ghanaian local artisans comply with safety regulations at their workplaces?

The extent of compliance with the requirements of Act 328 regarding the work environments of the local artisans were investigated based on certain parameters as presented in the table. The results indicated that most of their work places were spacious enough $(76.0 \%)$, had adequate provision of lighting $(90.0 \%)$ and were well ventilated $(81.0 \%)$. However, only a few of them had satisfactorily clean work environment $(25 \%)$, had workshops free from slips or trips $(26 \%)$ or had their equipment properly arranged $(31.3 \%)$. The results also 
Asamani, L.

showed that about $61.3 \%$ of the workshops had first aid boxes. However, the boxes were not kept at very good place and did not look very presentable. Considering the nature of the work that the artisans do, washing facilities should be a top priority at their work places. However, only 5.8\% of the workplaces surveyed had washing facilities for proper sanitation.

Table 2

Percentage s of Auto Artisans Complying with Health and Safety Regulations

\begin{tabular}{lc}
\hline \multicolumn{1}{c}{ Work Conditions } & Percentage \\
\hline Spacious working area & 76.00 \\
Clear and accessible exists from the work shop & 77.34 \\
Adequate provisions for lighting in the shop & 90.00 \\
Well ventilated workshop & 81.00 \\
Workshop always kept clean & 25.00 \\
Workshop free from slips/Trips & 26.00 \\
Oil spills on the ground are cleaned immediately & 26.83 \\
Washing facilities & 5.78 \\
Proper arrangement of equipment & 31.33 \\
Have first aid kits at the workplace & 61.33 \\
\hline
\end{tabular}

Research Question 2: What are the major health and safety challenges experienced by the local artisans?

The prevalence of the occurrence of various forms of occupational health and safety incidents among the local artisans are presented in table 3. The results showed that the artisans experienced several occupational health and safety incidents and disabilities. Among others, about $90 \%$ of the artisans reported having experienced headache related to their job. Waist pain, back pain, neck pain and many others were among the major incidents that the artisans experienced related to their work. Cuts or tool injuries were very common (84\%) among the artisans.

Table 3

Prevalence of Health and Safety Incidents among Auto Artisans

\begin{tabular}{lc}
\hline \multicolumn{1}{c}{ Health and Safety incident } & Percentage \\
\hline Headache & 90.00 \\
Waist pain & 88.67 \\
Back pain & 86.00 \\
Neck pain & 84.00 \\
Diarrhea & 34.00 \\
Vomiting & 28.67 \\
Heart palpitation & 38.67 \\
Fever and Dizziness & 54.00 \\
Skin infection & 44.67 \\
Sore ribs and chest pain & 40.00 \\
Fractured bones & 31.33 \\
Blurred visions & 46.67 \\
Suffocation & 46.00 \\
Knee problem & 63.00 \\
Hearing lose & 36.00 \\
Burns & 59.33 \\
Cuts & 84.00 \\
Witness of any death & 38.67 \\
Eye irritation & 49.33 \\
Electric shock & 38.00 \\
\hline
\end{tabular}

Generally, $90 \%$ of the respondents indicated that they had suffered some form of injury personally and had witnessed a work colleague injured (89\%) at the workplace within the past 12 months. Considering the nature of 
Safety compliance and prevalence of occupational health and safety incidents among Ghanaian auto artisans the work they engaged in, the researchers asked for evidence of first aid kits at the workplaces. The results showed that about $61.3 \%$ of the workshops had first aid kits.

\section{Table 4}

General Rates of Injury within the Past 12 Months

\begin{tabular}{lc}
\hline \multicolumn{1}{c}{ Items } & Percentage \\
\hline Suffered any injury at the workplace (last 12 months) & 90.00 \\
Any colleagues suffered any injury at work & 89.00 \\
\hline
\end{tabular}

Research Question 3: How do the local artisans treat health and safety challenges and injuries suffered at their workplaces?

The study also investigated how the artisans treated injuries that occurred at their workplace (see table 5). About 5.3\% indicated that there were no treatments involved, which suggests that they were not major incidents. Traditional treatment, where local herbalists were consulted for treatment constituted $8.7 \%$, with self-treatment being $48.7 \%$. Hospital treatments, which involved mainly serious incidents and injuries constituted $37.3 \%$ of the reported incidents.

\section{Table 5}

Mode of Treatment of Work Injuries and Incidents by Auto Artisans

\begin{tabular}{|c|c|}
\hline Type of treatment & Percentage \\
\hline No treatment & 5.33 \\
\hline Traditional treatment & 8.67 \\
\hline Self-treatment & 48.67 \\
\hline Hospital treatment & 37.33 \\
\hline & 100.00 \\
\hline
\end{tabular}

\section{Discussions of Findings}

\subsection{Auto artisans' compliance with safety regulations at their workplaces}

The results in this study show that Ghanaian local artisans are exposed to various forms of occupational hazards and they do not comply with safe work procedures and regulations. Some of the artisans thought the use of PPEs, for instance, inconveniences them in their work, while others though they were not necessary because they have been working without certain PPEs for years and that has become the norm. They feel the use of PPE therefore makes one looks odd among the peers at work. Ametepeh (2011) found in her study of informal sector workers that about $56 \%$ of local artisans were uncomfortable with the use of PPEs. The implication here is that the artisans are less informed about the need to use PPEs and comply with safe work practices and regulations as contained in the FOSA.

The provisions in the FOSA seem to be enforced to some extent, only in the formal sector. The inspectorate directorate of the Ministry of Employment and Labor Relations does not seem to see the local artisans work setting as part of their responsibility. The directorate sometimes complained of logistics constraints as a reason for not discharging the mandates conferred on it.

Another reason for the lack of compliance with the safety regulations could be the lack of availability and cost of required PPEs. Some of the PPEs that the artisans need for their work could not be easily obtained from the local markets. Where these are even available, the cost is prohibitive and so they decide to improvise or work without any PPE. There is a lack of compliance also with those regulations that do not require the use of PPEs, but general maintenance and cleanliness of the work place, such as arrangement of work tools and covering of naked electric cables. This could be attributed to general poor safety culture in the informal sector in particular 
and at most work place in Ghana in generally.

\subsection{Major health and safety challenges experienced by the artisans}

The study also found that the artisans experienced a lot of work-related accidents, injuries and illnesses. The hazardous nature of the work they do explains the rate of prevalence in this sector. The very nature of the materials, the work environment, tools and equipment they use make their work very hazardous which predisposed them to various health problems and injuries.

\section{Local Artisans: What do they do?}

Figure 1. Artisans at work

Note. Picture taken by the author

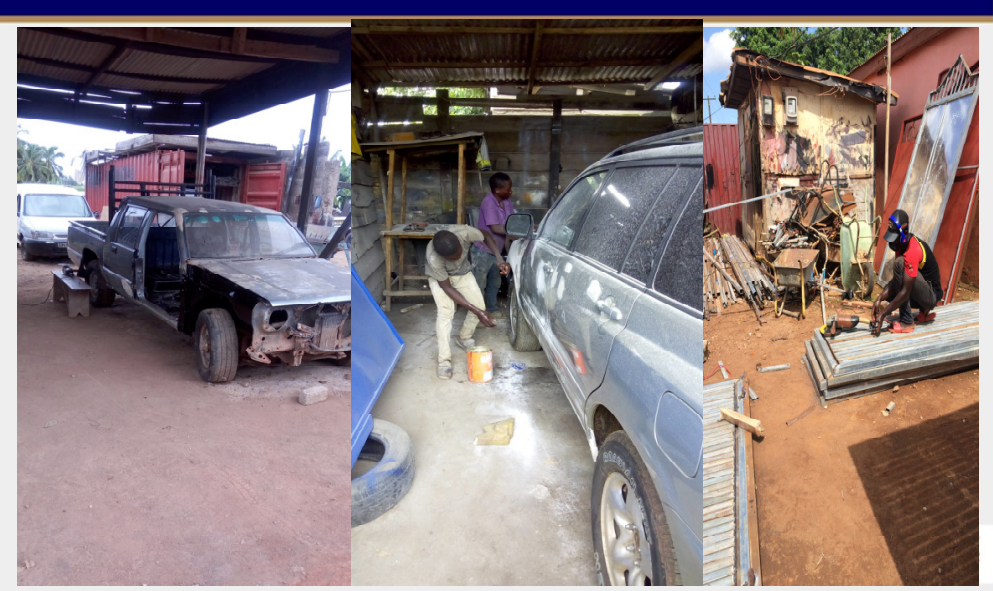

The work of a welder, for instance involves the use of electricity operated machines, sharp work tools and machines, sharp edge metals and sometimes working on the direct sun. This category of workers sufferers are also exposed to noise and vibration working for long hours on different machines (Ametepeh, 2011). All these and other elements of their work predispose them to harm and health challenges. The level of noise was found to result in hearing loss (Granneman, 2011) and complains of physical pains due to work posture (Ametepeh, 2011). The awkward sustained work postures in their work duties, lifting of heavy objects and sometimes, repetitive movement in performing work account for the prevalence of lower back pains, chest pains etc. Auto sprayers also come into contact with various forms of chemical components from the paint and other work solutions and materials they use. Granneman (2011) found auto artisans to be among the category of workers who use harmful chemicals in their operations.

The general lack of compliance with safe work practices could also explain the high rate of injuries and health challenges. In a hazardous work environment where most of the hazards cannot be eliminated, the only way to prevent harm or injuries from occurring from exposure to the hazards is the use of appropriate personal protective equipment (PPEs) and protective wears. The results in this study indicated that most the artisans do not comply with safety regulations.

\subsection{How Ghanaian local artisans treat health and safety challenges and injuries suffered at their workplaces}

The results suggest further that only a few of the incidents were not treated in any way. This means that those were minor incidents. Given that over $94 \%$ of the incidents were treated either at the hospital, traditionally or self-treatment, one can conclude that those were serious incidents that require attention. The cost of these incidents includes lost time, time off or absence from work and hospital bills.

The traditional treatments involve the use of herbal medicines to treat whatever incident the individual may 
Safety compliance and prevalence of occupational health and safety incidents among Ghanaian auto artisans

be suffering from. These are generally seen to be less expensive and more convenient than hospital treatment where there are always long queues and administrative processes. The self-treatment also involves balms, ointments, hot water and many others to massage the part affected by the incident at home. These are normally used in less severe cases which are manageable by the victims at home. When injuries or health problems are serious and beyond what the individual feels he or she can treat at home, they are usually taken to the hospital.

\section{Conclusions and Recommendations for Policy and Practice}

The study concluded that Ghanaian artisans are exposed to various forms of hazards, yet most of them do not comply with safe working procedures, resulting in various forms of injuries and disabilities. The findings brought to the fore the seriousness of the urgent need for enforcement of health and safety regulation across all sectors of the Ghanaian work settings. The findings also suggested that there were inadequate safety wears and equipment, making prices of the available ones beyond the affordability of the artisans.

The following recommendations were made based on the findings to help improve the health and safety situations of the local artisans.

$>\quad$ The Inspectorate Directorate should be inclusive in the application in implementation of the provisions in the Factories, Offices and Shops Act. Occasional monitoring of the work places of the local artisans would go a long way to prevent some of the incidents and boost the rate of compliance.

$>\quad$ Health and safety at work education and training should be regularly carried out for the local artisans. The cost of these training and education programmes would eventually be lower than the cost of poor health and safety culture and compliance. There are associations of auto artisans at some of the places this trade is carried out on large scale. The leadership of these associations could collaborate with local authority, District Chief Executives and other relevant stakeholders to educate the artisans about the need to take their safety and health seriously.

$>$ Government commitment to health and safety of all workers should be demonstrated through the provision of a comprehensive occupational health and safety policy that could be applied to all workers in Ghana.

$>$ Government could also demonstrate commitment by ensuring the availability of needed PPEs and resources for all workers in the country. The resources could also be in the form of competence health and safety practitioners in all Districts in the country to educate and train workers in safety issues.

Ghana needs to demonstrate commitment to the provision of decent work for all workers, irrespective of the sector, and ensure integrative and inclusive compliance with safety regulations if the sustainable development goals (SDG 2030), goal number 8 is to be achieved.

\section{References}

Ametepeh, R. S. (2011). Occupational health and safety of the informal service sector in the Sekondi-Takoradi Metropolitan Area. A thesis submitted to the School of Graduate Studies, Kwame Nkrumah University of Science and Technology, Kumasi.

Atim, C., Fleisher, L., Hatt, L., Masau, S., \& Arur, A. (2009). Universal access to quality health services: Improve maternal, neonatal and child health. Paper presented at the Fourth Session of the African Union Conference of Ministers of Health, Addis Ababa, Ethiopia, May 4-8, 2009.

Barling, J., Loughlin, C., \& Kelloway, E. K. (2002). Development and test of a model linking safety-specific transformational leadership and occupational safety. Journal of Applied Psychology, 87, 488-96. https://doi.org/10.1037/0021-9010.87.3.488

Boden, L. I., Biddle, E. A., \& Spieler, E. A. (2001). Social and economic impacts of workplace illness and 
injury :Current and future directions for research. American Journal of Industrial Medicine, 40(4), 398-402. https://doi.org/10.1002/ajim.10013

Ghana Department of Labor. (1999). Occupational health and safety report. Accra: Author.

Ghana Department of Labor. (2000). Occupational health and safety report. Accra: Author.

Ghana Living Standards Survey. (2014). Ghana living standards survey report of the sixth round: Poverty profile in Ghana (2005-2013) report. Accra: Ghana Statistical Service.

Ghana News Agency. (September 18, 2003). Economic cost of occupational injuries. Accra: Author

Government of Ghana. (1970). Factories, Offices and Shops Act of Ghana, Act 328. Accra: Assembly Press.

Government of Ghana. (1970). Minerals and Mining Law of Ghana. LI 665. Accra: Assembly Press.

Government of Ghana. (2003). Labour Act of Ghana, Act 651. Accra: Assembly Press.

Granneman, J. (2011). About metal working machine noise levels. Retrieved from http://www.peutz.fr

International Labor Organization. (2006). Occupational safety and health: Synergies between security and productivity, Geneva: WHO

International Labor Organization. (2014). Safety and health at work: A vision for sustainable prevention. Paper presented at the XX World Congress on Safety and Health at Work. Frankfurt. Geneva: International Labor Office.

International Labor Organization. (2015). Investigation of occupational accidents and diseases: A practical guide for labor inspectors. Geneva: International Labor Office.

Mock, C., Adjei, S., Acheampong, F., Deroo, L., \& Simpson, K. (2005). Occupational injuries in Ghana. International Journal of Occupational and Environmental Health, 11, 238-245. https://doi.org/10.1179/oeh.2005.11.3.238

Munteanu, D. S., (2005). Improving machine translation performance by exploiting non-parallel corpora. Computational Linguistics, 31(4), 477-504. https://doi.org/10.1162/089120105775299168

Osei-Boateng, C., \& Ampratwum, E. (2011). The informal sector in Ghana. Accra: Friedrich Ebert Stiftung.

World Health Organisation. (1999). Occupational Heath: Ethically correct, economically sound, Geneva, Switzerland: Author

World Health Organization. (2010). WHO healthy workplace framework and model: Background and supporting literature and practices. Geneva: Author. 